\title{
Regional citrate anticoagulation for pediatric CRRT using integrated citrate software
}

\author{
Jean-Michel Liet • Gwenaelle Roussey
}

Received: 18 April 2014 /Revised: 4 June 2014 / Accepted: 5 June 2014 / Published online: 7 August 2014

(C) IPNA 2014

Dear Editors,

We have reported in Pediatric Nephrology a new procedure of regional citrate anticoagulation, using integrated citrate software, commercially available solutions containing physiological sodium concentrations, and simplified procedures to perform continuous renal replacement therapy in children (CRRT) [1]. In this procedure, we injected calcium into the return line of the hemofiltration catheter, and not in a separate central line, for vein preservation purposes in these children at risk of chronic kidney disease. This strategy was previously used in adults [2]. We noticed no complications for children weighing more than $15 \mathrm{~kg}$ when using a blood flow rate higher than $50 \mathrm{ml} / \mathrm{min}$.

Since this report, we have performed the same procedure in younger children and recently we noticed clotting in the return line in a 7-month-old child weighing $7.9 \mathrm{~kg}$. The blood flow rate was set at $30 \mathrm{ml} / \mathrm{min}$. A clot was observed in the pulmonary artery using cardiac echography performed at the same time for the evaluation of systemic hypertension. Renal replacement therapy was stopped and no clinical complications occurred thereafter. We would therefore like to warn readers about this potentially serious complication.

We consider that this clotting in the return line was facilitated by the low flow and also by the infusion of calcium into the venous return line of a dual-lumen catheter that normalizes coagulation before the end of this extracorporeal circulation. No other predisposing factor has been found; thus, we no longer perform calcium infusion into the return line. Henceforth, to maintain our strategy of vein preservation, we try to use triple lumen central venous catheters to perform hemofiltration when another central line is not already available for the calcium infusion. Unfortunately, only 12-French triple lumen catheters are commercially available for hemofiltration and these are not suitable for young children. Standard triple lumen 7.5-French catheters can tolerate a blood flow rate up to $50 \mathrm{ml} / \mathrm{min}$ but are not designed for hemofiltration. We hope that our change in practice will prevent clot formation at the distal portion of the CRRT course.

\section{References}

1. Liet JM, Allain-Launay E, Gaillard-Leroux B, Barrière F, Chenouard A, Dejode JM, Joram N (2014) Regional citrate anticoagulation for pediatric CRRT using integrated citrate software and physiological sodium concentration solutions. Pediatr Nephrol. doi:10.1007/ s00467-014-2770-2

2. Dorval M, Madore F, Courteau S, Leblanc M (2003) A novel citrate anticoagulation regimen for continuous venovenous hemodiafiltration. Intensive Care Med 29:1186-1189

\author{
J.-M. Liet $(\bowtie)$ \\ Unité de Réanimation Pédiatrique, Pôle Femme-Enfant-Adolescent, \\ CHU of Nantes, Nantes, France \\ e-mail: jeanmichel.liet@chu-nantes.fr \\ G. Roussey \\ Unité de Néphrologie Pédiatrique, Clinique Médicale Pédiatrique, \\ Pôle Femme-Enfant-Adolescent, CHU of Nantes, Nantes, France
}

